\title{
Acute Hemorrhagic Cholecystitis with Large Hemoperitoneum: Treatment with Microcoil Embolization and Subsequent Cholecystectomy
}

\author{
Don Nguyen $^{1 *}$, Scott Goodwin ${ }^{2}$, Nirjhor Bhowmik ${ }^{3}$, Guillaume Boiteau ${ }^{4}$, Jonathan Potts ${ }^{4}$ \\ 1. Department of Abdominal Imaging \& Intervention, Brigham and Women's Hospital, Harvard Medical School, Boston, USA \\ 2. Department of Diagnostic Radiology, Duke University Hospital, Durham, USA \\ 3. Department of Vascular \& Interventional Radiology, Medical College of Wisconsin, Wauwatosa, USA \\ 4. Department of Vascular \& Interventional Radiology, Allegheny Health Network, Pittsburgh, USA
}
* Correspondence: Don Nguyen, MD, MHA, Department of Abdominal Imaging \& Intervention, Brigham and Women's Hospital, Harvard Medical School, 75 Francis Street, Boston, MA 02115, USA $\triangle$ dnguyen5@bwh.harvard.edu)

Radiology Case. 2021 Feb; 15(2):25-34 :: DOI: 10.3941/jrcr.v15i2.3901

\begin{abstract}
Hemorrhagic cholecystitis is a potentially deadly and difficult to recognize entity. It is associated with cystic artery pseudoaneurysm and is usually seen in the setting of acute calculous cholecystitis. We report two cases of hemorrhagic cholecystitis with arteriographic findings of cystic artery pseudoaneurysms that were successfully embolized using microcoils, facilitating subsequent cholecystectomy. Both cases had unusual presentations of gallbladder rupture with hemoperitoneum, the latter of which was atypical occurring in the absence of gallstones. We believe when hemorrhagic cholecystitis is suspected, a two-step therapeutic approach should be employed with embolization of the bleeding cystic artery followed by cholecystectomy. A comprehensive literature review and discussion of hemorrhagic cholecystitis will be provided.
\end{abstract}

\section{CASE REPORT}

\section{CASE REPORT}

Case Report 1: Calculous hemorrhagic cholecystitis (typical)

A 74-year-old white male with a history of atrial fibrillation on coumadin was referred from an outside hospital with a 5-day history of abdominal pain, nausea, and vomiting, followed by 2 days of severe right upper quadrant pain. He experienced no hematemesis or melena. His physical examination was significant for abdominal tenderness, particularly in the right upper quadrant and epigastric region. A hepatic panel revealed markedly elevated aspartate aminotransferase (AST), alanine aminotransferase (ALT), and total bilirubin. The patient's coagulation studies were only mildly elevated. Of greater clinical concern, however, laboratory values showed a significant drop in hemoglobin at $6.4 \mathrm{~g} / \mathrm{dL}$ (normal: $14-17.4 \mathrm{~g} / \mathrm{dL}$ ) compared to $12.3 \mathrm{~g} / \mathrm{dL}$ at the outside hospital.

A CT of the abdomen and pelvis performed at the outside hospital revealed right upper quadrant hematoma and hemoperitoneum around the liver and spleen. In addition, a 1$\mathrm{cm}$ gallstone was impacted at the gallbladder neck with suggestion of erosion of the gallbladder wall. An ultrasound 
was performed at our institution and demonstrated a diffusely heterogeneous gallbladder with intraluminal blood products and a thickened, discontinuous wall suspicious for perforation (Figure 1). There was no sonographic evidence of cholelithiasis on ultrasound, which was likely obscured by intraluminal hemorrhage, and Doppler evaluation showed no evidence of active bleeding.

Arteriography was requested to identify the source of the bleeding. From a right femoral approach, a 5-French Mickelson catheter (Cook Medical, Bloomington, IN) was used to catheterize the celiac trunk and common hepatic artery. The cystic artery harboured two small pseudoaneurysms with no visible contrast extravasation (Figure 2A). The Mickelson catheter was exchanged for a 4French Cobra catheter (Cobra C2 Glidecath; Terumo Medical, Somerset, NJ) introduced into the origin of the cystic artery. A 3-French microcatheter (Renegade Hi-Flo; Boston Scientific, Natick, MA) was then advanced through the base catheter, and two $2 \times 3 \mathrm{~mm}$ and two $2 \times 4 \mathrm{~mm}$ microcoils (Interlock microcoils; Boston Scientific, Natick, MA) were deployed in the proximal cystic artery. This resulted in successful exclusion of both pseudoaneurysms (Figure 2B).

Subsequent open cholecystectomy performed the same day confirmed hemorrhagic cholecystitis with rupture of the gallbladder and large hematoma eroding into the right lobe of the liver. Approximately 1.5 liters of blood were removed during surgery. A gallbladder fossa drain was placed, and the patient recovered in the intensive care unit. Although the patient was discharged with no residual symptoms, he represented seven weeks later with fever and chills. Repeat CT scan of the abdomen and a cholangiogram through the indwelling gallbladder fossa drain revealed an unresected base of the gallbladder containing the original gallstone (Figure 3). Poor intraoperative visualization from large pericholecystic hemorrhage as noted in the operative report likely contributed to the incomplete cholecystectomy. The patient was later scheduled for elective total cholecystectomy and has been asymptomatic to date.

\section{Case Report 2: Acalculous hemorrhagic cholecystitis (atypical)}

A 74-year-old white male with coronary artery disease, hypertension, dyslipidemia, and diabetes was admitted for suspicion of mediastinitis following a recent sternotomy for coronary artery bypass grafting. The patient later developed acute renal failure, which required haemodialysis treatments beginning 10 days before this new hospitalization. Among his multiple cardiovascular medications, he was also receiving aspirin $325 \mathrm{mg}$ daily.

Initial investigation included an Indium-111 white blood cell scan that was positive for sternal infection, for which he was treated with intravenous antibiotics. CT scans of the chest, abdomen, and pelvis on hospital days 2 and 9 showed a distended gallbladder containing hyperdense dependant material, interpreted as sludge (Figure 4A, 4B). There was no gallstone or biliary dilatation and the patient denied abdominal/right upper quadrant pain at that time.
Ultrasound on day 7 revealed thrombosis in bilateral upper extremity superficial veins and in the right common femoral vein, which prompted treatment with heparin. An abdominal ultrasound on day 16 demonstrated moderate cholecystomegaly with generalized irregular mural thickening and a large amount of intraluminal sludge (Figure 4C). There was no sonographic evidence of cholelithiasis or pericholecystic fluid.

On day 17 , the patient became acutely hypotensive with progressive abdominal distension. A hepatic panel was unremarkable, but the patient's coagulation parameters were elevated after receiving heparin and aspirin. In addition, laboratory values revealed a significant decrease in hemoglobin compared to initial values on admission, from $10.7 \mathrm{~g} / \mathrm{dL}$ to $5.8 \mathrm{~g} / \mathrm{dL}$ (normal: $14-17.4 \mathrm{~g} / \mathrm{dL}$ ). An emergent CT scan of the abdomen (Figure 5) revealed massive and diffuse intraperitoneal hemorrhage, predominately in the right upper quadrant. The gallbladder was largely distended with blood, measuring $12 \times 7 \mathrm{~cm}$, and was presumed to be the culprit for the patient's large hemoperitoneum.

The patient was then referred for arteriography to determine the source of bleeding. From a right femoral access, a 5-French Simmons I catheter (Terumo Medical, Somerset, $\mathrm{NJ})$ was used to catheterize the celiac trunk and the superior mesenteric artery (SMA). The angiographic images showed a replaced right hepatic artery from the proximal SMA. Originating from this right hepatic artery, there was an irregular cystic artery with an actively bleeding pseudoaneurysm at the proximal and medial portion (Figure 6A). Active contrast extravasation could be seen flowing into the gallbladder lumen, delineating the medial border of the gallbladder (Figure 6B). A 3-French microcatheter (Renegade Hi-Flo; Boston Scientific, Natick, MA) was advanced to the proximal cystic artery, and embolization was performed with polyvinyl alcohol (PVA) particles (500-700 microns) (Contour; Boston Scientific, Natick, MA) by seven 3 x $30 \mathrm{~mm}$ and 4 x $30 \mathrm{~mm}$ microcoils (VortX microcoils; Boston Scientific, Natick, MA). This resulted in successful embolization of the cystic artery. Post-embolization images showed no opacification of the pseudoaneurysm and cessation of active extravasation/bleeding (Figure 6C).

The patient was hemodynamically stable shortly after embolotherapy. The following day, the patient was brought to the operating room and an open cholecystectomy confirmed gangrenous acalculous cholecystitis. The massive hemoperitoneum was evacuated with 9 liters of blood removed. He had an unremarkable postoperative course and was discharged 5 days later.

\section{DISCUSSION}

\section{Etiology \& Demographics:}

Gallstones are estimated to affect 10-20\% of Americans, and up to one out of three will eventually develop acute cholecystitis, making cholecystectomy the most commonly performed surgical procedure by general surgeons [1]. 
However, hemorrhagic cholecystitis remains a rare phenomenon. The exact prevalence of the disease is unknown as review of the literature is composed of isolated case reports.

The pathophysiology of hemorrhagic cholecystitis is believed to parallel calculous cholecystitis, beginning with gallbladder obstruction. This results in increased intraluminal pressure and compromised blood flow leading to subsequent mucosal ischemia, necrosis, and erosion [2]. The hemorrhagic component is most often related to the presence of cholelithiasis causing pressure erosions of the already ischemic and more fragile cystic artery and/or its branches [3]. Disruption of the vessel wall leads to formation of a pseudoaneurysm. This appears to occur most commonly with gallstones impacted at the gallbladder neck with erosion of the adjacent and proximal main cystic artery [4,5]. However, this may still occur in the setting of non-impacted stones eroding the gallbladder wall and smaller cystic arterial branches [6]. Notably, the erosion/necrosis of the cystic artery happens much more commonly than the ensuing hemorrhagic cholecystitis. Therefore, it has been speculated that this discordance is because most of the damaged cystic arteries undergo spontaneous thrombosis, resulting in self-occlusion [7].

A hypocoagulable state and/or platelet dysfunction such as in chronic dialysis patients may increase the likelihood of gallbladder hemorrhage in the setting of cholecystitis, or in rare cases may even lead to spontaneous gallbladder hemorrhage in the absence of cholecystitis [8]. In addition, atherosclerosis is an important predisposing factor as the diseased cystic artery becomes more brittle and thus susceptible to gallstone pressure/erosion [8]. Among the other causes of gallbladder hemorrhage, the most common is iatrogenic (i.e. liver biopsy), followed by trauma [9]. Biliary neoplasms, parasites, and varices from portal hypertension are less frequent etiologies [10].

\section{Clinical \& Imaging Findings:}

Hemorrhagic cholecystitis may present with different manifestations. Once the bleeding cystic artery pseudoaneurysm begins filling the gallbladder lumen with blood, the hemorrhage may remain confined to the gallbladder and clinically mimic classical cholecystitis [10]. Hemorrhagic cholecystitis is unlikely to be suspected before surgical resection unless radiologic workup helps to identify the underlying pathology.

Alternatively, the hemorrhage may escape the gallbladder through the cystic duct. If blood clots develop in the common hepatic duct, it can obstruct the biliary system and result in jaundice. However, if a significant amount of blood escapes through the ampulla of Vater, the patient will present with gastrointestinal bleeding. The combination of these signs and symptoms is referred to as hemobilia. The classical triad (Quincke's triad) associated with hemobilia includes colicky biliary pain, icteric state, and gastrointestinal bleeding (hematemesis and melena), which has been reported in about one third of patients [11].

Uncommonly, the patient may present with hemoperitoneum. This occurs with active gallbladder bleeding from a cystic artery pseudoaneurysm in combination with an obstructed cystic duct, which prevent the blood from decompressing into the biliary and gastrointestinal systems. Subsequently, the hyperpressurized, blood-distended gallbladder will rupture leading to hemoperitoneum [5].

\section{Endoscopy:}

Gastroduodenoscopy is an important tool in the diagnosis of upper gastrointestinal hemorrhage as up to $90 \%$ of cases are related to diseases of the digestive tract such as peptic ulcers or gastroesophageal varices [12]. However, in cases of hemorrhagic cholecystitis, gastroduodenoscopy findings may be negative if the bleeding gallbladder has an obstructed cystic duct. In the absence of such an obstruction, endoscopy will reveal blood coming from the ampulla of Vater (hemobilia) in up to $50 \%$ of cases, with or without associated intestinal blood [13]. Endoscopic retrograde cholangiopancreatography (ERCP) may show filling defects (clots) in the biliary ducts and can also allow for ductal decompression. It is important to note that if a gastroduodenal ulcer is identified, it may be mistaken for the source of bleeding and would delay proper diagnosis and treatment [7]. Therefore, an upper endoscopy can orient the investigation by revealing hemobilia, but usually will not identify the exact origin of the hemorrhage or offer definitive treatment $[13,14]$.

\section{Non-invasive imaging:}

Radiographic imaging plays a key role in identifying hemorrhagic cholecystitis. Frequently, ultrasound, CT, and MRI will demonstrate imaging features seen with classical cholecystitis including gallbladder wall thickening, gallstones, and pericholecystic fluid/infiltration. While intraluminal blood products may appear similar to biliary sludge on ultrasound and CT, MRI allows for differentiation by demonstrating blood product signal (hyperintense $\mathrm{T} 1$ and isointense/hypointense T2). The most specific imaging finding for hemorrhagic cholecystitis is the identification of a cystic artery pseudoaneurysm. Contrast-enhanced CT will demonstrate the densely enhancing pseudoaneurysm in the gallbladder lumen as well as detect active contrast extravasation [2]. Ultrasound Doppler imaging can also reveal cystic artery pseudoaneurysms and help to orient the investigation in the right direction [14].

\section{Arteriography:}

Arteriography is the modality that can identify the source of bleeding when the rate of bleeding is $>0.5 \mathrm{~mL} / \mathrm{min}$, and it has the advantage of offering a minimally-invasive therapeutic option concomitantly. The literature reports up to $90 \%$ sensitivity for arteriography in detecting the source of hemobilia [15]. As timely diagnosis of this rare and potentially fatal entity is critical, once the diagnosis of a hemorrhagic cholecystitis is suspected, diagnostic and therapeutic arteriography should be part of the management algorithm.

\section{Treatment \& Prognosis:}

Diagnostic arteriography should be immediately followed by definitive treatment consisting of cholecystectomy with ligation of the cystic artery [4]. Pre-cholecystectomy embolotherapy has several reported advantages such as hemodynamic stabilization with rapid cessation of 
hemorrhage. In addition, it allows additional time for preoperative surgical planning and helps to minimize operative blood loss during surgery.

Embolotherapy is performed with a coaxial system. A 5 or $6 \mathrm{~F}$ base catheter is advanced to the proximal celiac artery and a microcatheter is then used to selectively catheterize the cystic artery. Different agents may be used for embolization of the cystic artery pseudoaneurysm, including microcoils, Gelfoam, and n-butyl cyanoacrylate [13,16,17]. Microcoils are generally the preferred method as they come in various sizes, offer a high degree of localization and control, and can be introduced without increasing intraluminal pressure [16,17]. nButyl cyanoacrylate solidifies rapidly and thus requires operator experience, but also offers certain advantages including its ability to occlude pseudoaneurysms with complex shapes consisting of many small, tortuous arteries and collateral vessels that cannot be super-selected for coil delivery [18]. Gelfoam can also be used, though it can increase intraluminal pressure risking rupture and may lead to embolization more distally than desired [16,17]. Since the cystic artery and its branches are terminal circulation, retrograde or collateral flow is not expected. Therefore, the coils are placed as proximal as possible to the cystic artery pseudoaneurysm. The final angiographic result should show no flow beyond the coils and thus no opacification of the cystic artery pseudoaneurysm. However, if cannulation of the cystic artery is technically challenging, the right hepatic artery could theoretically be embolized. It is important to prove that the portal vein is patent to minimize the risk of hepatic ischemia.

Subsequent cholecystectomy is usually performed on the same day or the day following embolization because of the theoretical fear that the occluded cystic artery will lead to more gallbladder ischemia and gangrene. However, after embolotherapy, some patients underwent cholecystectomy up to 10 days later with no report of complications linked to this delay [4]. For patients who are not surgical candidates, embolization of the bleeding cystic artery followed by percutaneous cholecystostomy is an alternative option [7]. Recent advances have introduced additional options for patients who undergo cholecystostomy including cholecystoscopy with subsequent cholecystolithotomy to remove gallstones, and even electrohydraulic or laser cholecystolithotripsy for stones that are too large to be removed through the sheath [19,20]. Gallbladder cryoablation, which has recently been reported to achieve occlusion of the cystic duct and involution of the gallbladder, rendering the patient functionally acholecystic, represents another potential option for these patients [21].

The prognosis for patients with hemorrhagic cholecystitis is quite variable depending on clinical presentation. While it is a rare entity, complications from hemorrhagic cholecystitis are not, and it is potentially fatal if not detected. Early diagnosis is essential to facilitate urgent intervention and surgical treatment. A summary of key points related to hemorrhagic cholecystitis is provided in Table 1 .

\section{Differential Diagnoses}

Hemorrhagic cholecystitis is a difficult diagnosis to make given the similarities in presentation and imaging findings to more common diagnoses of the hepatobiliary tract. Imaging finds for the following differential diagnoses are summarized in Table 2.

\section{Acute Cholecystitis}

Hemorrhage into the gallbladder may lead to clot causing obstruction of the cystic duct, resulting in a mechanism very similar to that of acute calculous cholecystitis. Given similarities in clinical presentation and imaging findings that are often misleading, hemorrhagic cholecystitis is often confused with acute calculous cholecystitis [22]. Hemorrhagic cholecystitis may be differentiated by the presence of hematemesis, melena, or the passage of blood through the ampulla of Vater during endoscopy, which may be accompanied by a decrease in hematocrit [23]. However, such bleeding may occur in the setting of cholelithiasis/acute calculous cholecystitis, as gallstone-related microbleeding accounts for as much as $9 \%$ of hemobilia cases [24]. The presence of symptoms consistent with Quincke's triad (colicky biliary pain, jaundice, gastrointestinal bleeding) suggests cystic artery pseudoaneurysm, and should therefore increase suspicion for hemorrhagic cholecystitis [23].

\section{Intraluminal Gallbladder Mass/Carcinoma}

Agglomerated blood inside the gallbladder may mimic a mass [2]. Doppler analysis is useful to identify blood flow within the mass if it is a solid vascular lesion. It is important to be aware that on sonography, acute extravasation of blood between clot interstices can mimic blood vessels inside a mass ("pseudo-artery" sign), leading to the wrong diagnosis [25]. Additionally, gallbladder polyps and carcinomas can result in focal or diffuse mural thickening that can resemble the wall thickening seen in hemorrhagic cholecystitis [26].

\section{Biliary Sludge}

Dense gallbladder content is typically seen with hemorrhagic cholecystitis and may be misinterpreted as biliary sludging. Ultrasound will show echogenic debris and CT will show dense intralumenal material. MRI, however, will allow differentiation from sludge by demonstrating blood product signal (hyperintense T1 and isointense/hypointense T2).

\section{TEACHING POINT}

Classical symptoms of hemobilia are often absent and therefore it is important to consider the prospect of hemorrhagic cholecystitis in patients presenting with biliary symptoms associated with gastrointestinal bleeding, unexplained upper abdominal hemoperitoneum, or imaging findings suggestive of pericholecystic or gallbladder blood products. Once identified, a two-step therapeutic approach is recommended with embolization of the culprit vessel to stop the bleeding and stabilize the patient for subsequent cholecystectomy, which remains the ideal definitive treatment in surgical candidates. 


\section{REFERENCES}

1. Bloom A. Cholecystitis: Practice Essentials, Background, Pathophysiology. 2019 Nov 10 [cited 2020 May 12]; Available

from:

https://emedicine.medscape.com/article/171886-overview\#a6

2. Gremmels JM, Kruskal JB, Parangi S, Kane RA. Hemorrhagic cholecystitis simulating gallbladder carcinoma. J Ultrasound Med. 2004 Jul;23(7):993-995. PMID: 15292572

3. Naqvi MA, Danese CA, Dreiling DA. Intraperitoneal hemorrhage as a complication of acute ruptured cholecystitis. J Mt Sinai Hosp N Y. 1968 Aug;35(4):396-407. PMID: 5243527

4. Maeda A, Kunou T, Saeki S, Aono K, Murata T, Niinomi N, Yokoi S. Pseudoaneurysm of the cystic artery with hemobilia treated by arterial embolization and elective cholecystectomy. J Hepatobiliary Pancreat Surg. 2002;9(6):755-758. PMID: 12658412

5. Radouane B, Jidal M, El Fenni J, Chaouir S, Amil T, Hanine A, Benameur M. DIG71 Faux anevrisme de l'artere cystique?: une complication rare de cholecystite aigue. Journal de Radiologie. 2006 Oct 1;87(10):1472-1473.

6. Sandblom P, Mirkovitch V. Hemobilia: some salient features and their causes. Surg Clin North Am. 1977 Apr;57(2):397-408. PMID: 322339

7. Delgadillo X, Berney T, de Perrot M, Didier D, Morel P. Successful treatment of a pseudoaneurysm of the cystic artery with microcoil embolization. J Vasc Interv Radiol. 1999 Jun;10(6):789-792. PMID: 10392949

8. Morris DS, Porterfield JR, Sawyer MD. Hemorrhagic Cholecystitis in an Elderly Patient Taking Aspirin and Cilostazol. Case Rep Gastroenterol. 2008 Jun 23;2(2):203207. PMID: 21490889

9. Ellington RT, Seidel RH, Burdick JS, Peterson WL, Harford WV. Acalculous cholecystitis presenting as hemobilia and jaundice. Gastrointest Endosc. 2000 Feb;51(2):218-220. PMID: 10650274

10. Pandya R, O'Malley C. Hemorrhagic cholecystitis as a complication of anticoagulant therapy: role of $\mathrm{CT}$ in its diagnosis. Abdom Imaging. 2008 Dec;33(6):652-653. PMID: 18629579

11. Brady E, Welch JP. Acute hemorrhagic cholecystitis causing hemobilia and colonic necrosis. Dis Colon Rectum. 1985 Mar;28(3):185-187. PMID: 3971827

12. Earthman W, Keller FS, Aldrete JS. Hemobilia. Management by percutaneous transcatheter embolization. Ala J Med Sci. 1987 Apr;24(2):155-157. PMID: 3578706

13. Shramek JK, Cooper SG, Wickremesinghe PC. Massive hemobilia resulting from gallstone erosion of the cystic artery: percutaneous transcatheter embolization as a temporizing measure--case report. J Vasc Interv Radiol. 1993 Jun;4(3):373-375. PMID: 8513210

14. Nakajima $M$, Hoshino $H$, Hayashi $E$, Nagano $K$, Nishimura D, Katada N, Sano H, Okamoto K, Kato K. Pseudoaneurysm of the cystic artery associated with upper gastrointestinal bleeding. J Gastroenterol. 1996 Oct;31(5):750754. PMID: 8887048

15. Artigas JM, Martí M, Soto JA, Esteban H, Pinilla I, Guillén E. Multidetector CT angiography for acute gastrointestinal bleeding: technique and findings. Radiographics. 2013 Oct;33(5):1453-1470. PMID: 24025935

16. Desai AU, Saunders MP, Anderson HJ, Howlett DC. Successful Transcatheter Arterial Embolisation of a Cystic Artery Pseudoaneurysm Secondary to Calculus Cholecystitis: A Case Report. J Radiol Case Rep. 2010 Feb 1;4(2):18-22. PMID: 22470707

17. Tapnio RH, Kolber MK, Shukla PA, Berkowitz E. Transcatheter Embolization of Cystic Artery Pseudoaneurysms Secondary to Acute Cholecystitis. Vasc Endovascular Surg. 2017 Oct;51(7):498-500. PMID: 28782418

18. Won Y, Lee SL, Kim Y, Ku YM. Clinical efficacy of transcatheter embolization of visceral artery pseudoaneurysms using N-butyl cyanoacrylate (NBCA). Diagnostic and Interventional Imaging. 2015 Jun 1;96(6):563-569.

19. Kim SK, Mani NB, Darcy MD, Picus DD. Percutaneous Cholecystolithotomy Using Cholecystoscopy. Techniques in Vascular and Interventional Radiology. 2019 Sep 1;22(3):139148. PMID: 31623754

20. Srinivasa RN, Patel N, Hage AN, Chick JFB. Interventional Radiology-Operated Cholecystoscopy and Cholecystolithotripsy: A Guide for Interventionalists. Journal of Vascular and Interventional Radiology. $2018 \mathrm{Apr}$ 1;29(4):585. PMID: 29395901

21. McGregor H, Woodhead G, Conrad M, Tang A, Ruiz D, Khan A, Hennemeyer C. First in-Human Gallbladder Cryoablation in a Patient with Acute Calculous Cholecystitis Initially Treated with a Cholecystostomy Tube. Journal of Vascular and Interventional Radiology. 2019 Aug 1;30(8):1229-1232. PMID: 31003847

22. Parekh J, Corvera CU. Hemorrhagic cholecystitis. Arch Surg. 2010 Feb;145(2):202-204. PMID: 20157090

23. Di Muzio B, Shah V. Hemorrhagic cholecystitis | Radiology Reference Article Radiopaedia.org [Internet]. Radiopaedia. [cited 2020 May 12]. Available from: https://radiopaedia.org/articles/haemorrhagiccholecystitis?lang=us

24. Yoshida J, Donahue PE, Nyhus LM. Hemobilia: review of recent experience with a worldwide problem. Am J Gastroenterol. 1987 May;82(5):448-453. PMID: 3578223 
25. Ring EJ, Athanasoulis CA, Waltman AC, Baum S. The pseudo-vein: an angiographic appearance of arterial hemorrhage. J Can Assoc Radiol. 1973 Sep;24(3):242-244. PMID: 4543094
26. Weerakkody Y, Radswiki. Gallbladder carcinoma | Radiology Reference Article Radiopaedia.org [Internet]. Radiopaedia. [cited 2020 May 12]. Available from: https://radiopaedia.org/articles/gallbladder-carcinoma1?lang=us\#nav_differential-diagnosis

\section{FIGURES}
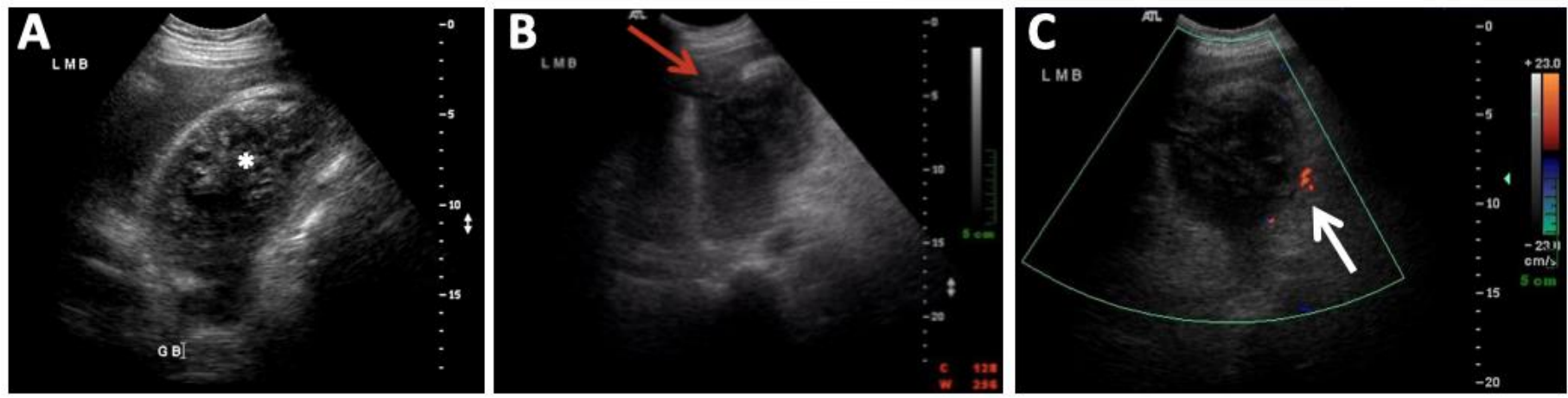

Figure 1: 74-year-old male with calculous hemorrhagic cholecystitis.

FINDINGS: A) Abdominal ultrasound showed a diffusely heterogeneous gallbladder with intraluminal blood products (*), (B) a thickened, discontinuous wall suspicious for perforation (red arrow), and positive sonographic Murphy's sign. There was no sonographic evidence for cholelithiasis (C) and Doppler evaluation showed normal peripheral (white arrow) but no internal color signal to suggest active bleeding.

TECHNIQUE: Real time ultrasound of the gallbladder using curved array transducer at $4 \mathrm{MHz}$.
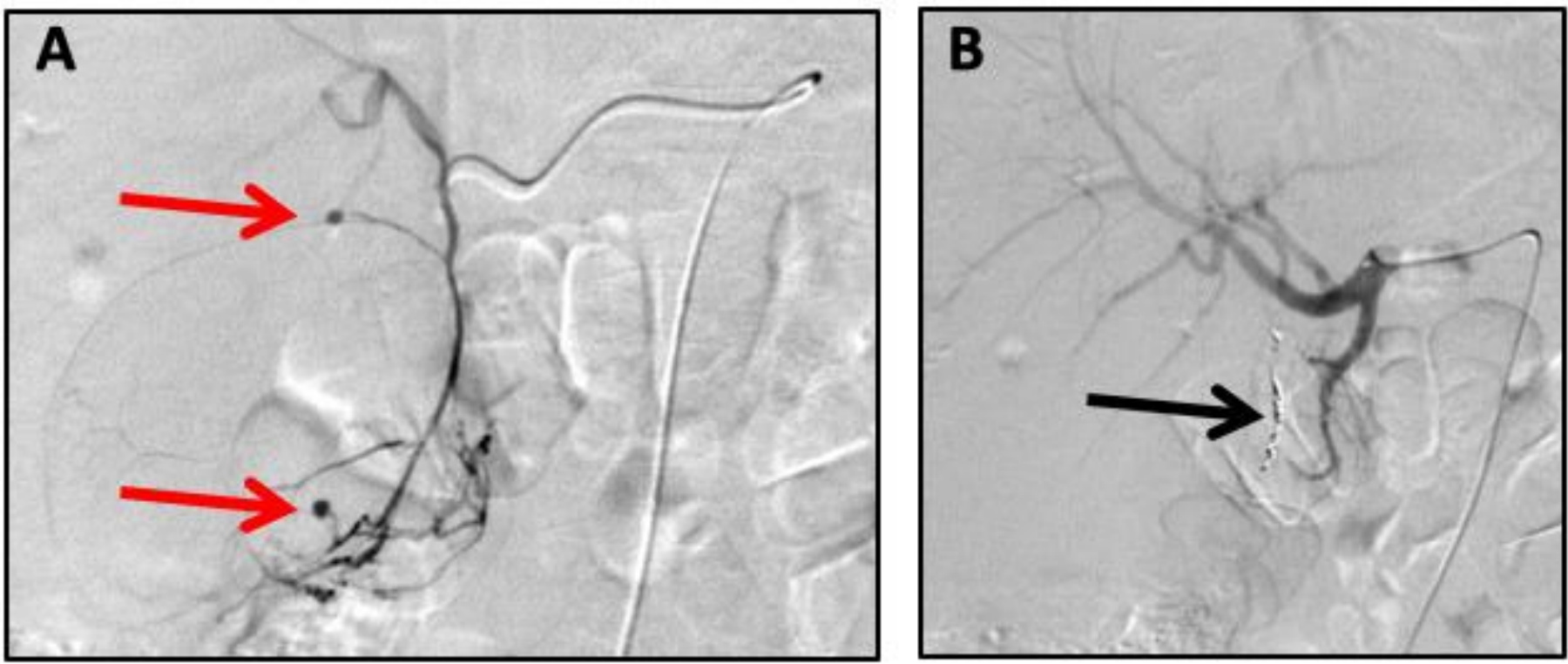

Figure 2: 74-year-old male with calculous hemorrhagic cholecystitis.

FINDINGS: A) Arteriography showed the cystic artery originating from the right proximal hepatic artery, normal origin. There were two small pseudoaneurysms (red arrows), (B) which were successfully excluded by proximal microcoil embolization (black arrow) of the cystic artery.

TECHNIQUE: Celiac angiography with sub-selective catheterization of the cystic artery was performed, followed by microcoil embolization of the cystic artery pseudoaneurysms. Embolization material: Two $2 \times 3 \mathrm{~mm}$ and two $2 \times 4 \mathrm{~mm}$ microcoils (Interlock microcoils; Boston Scientific, Natick, MA). Contrast: $181 \mathrm{~mL}$ Omnipaque-240. Fluoroscopy time: 20.8 minutes. Cumulative dose: $1550 \mathrm{mGy}$. Dose Area Product: $49130.97 \mathrm{mGym}^{2}$. 

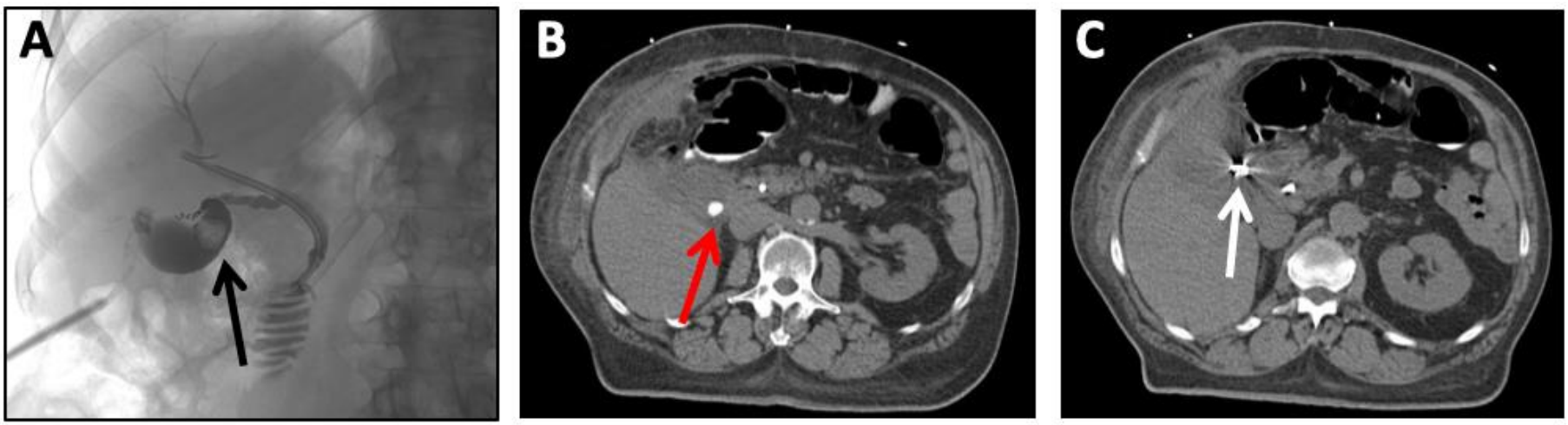

Figure 3: 74-year-old male, re-presenting 7 weeks after diagnosis of calculous hemorrhagic cholecystitis status post cystic artery embolization and incomplete cholecystectomy.

FINDINGS: A) Cholangiogram through the indwelling gallbladder fossa drain shows the unresected base of the gallbladder with filling defect (black arrow) along the dependent portion, (B) consistent with the residual gallstone seen on corresponding CT (red arrow). C) Non-contrast CT at the level of the gallbladder also demonstrates the microcoils/star artifact (white arrow) in the proximal cystic artery.

TECHNIQUE: A) Under fluoroscopic guidance, $125 \mathrm{~mL}$ of water-soluble contrast (Omnipaque-240) was injected through the indwelling gallbladder fossa surgical drain. Fluoroscopy time: 3.2 minutes, Cumulative Dose: 106.90 mGy, Dose Area Product: $2469.74 \mathrm{mGym}^{2}$

B) and C) Axial CT of the abdomen without oral or intravenous contrast. mAs per slice: $226 \mathrm{mAs}$, kilovoltage: $120 \mathrm{kV}$, slice thickness: $5 \mathrm{~mm}$
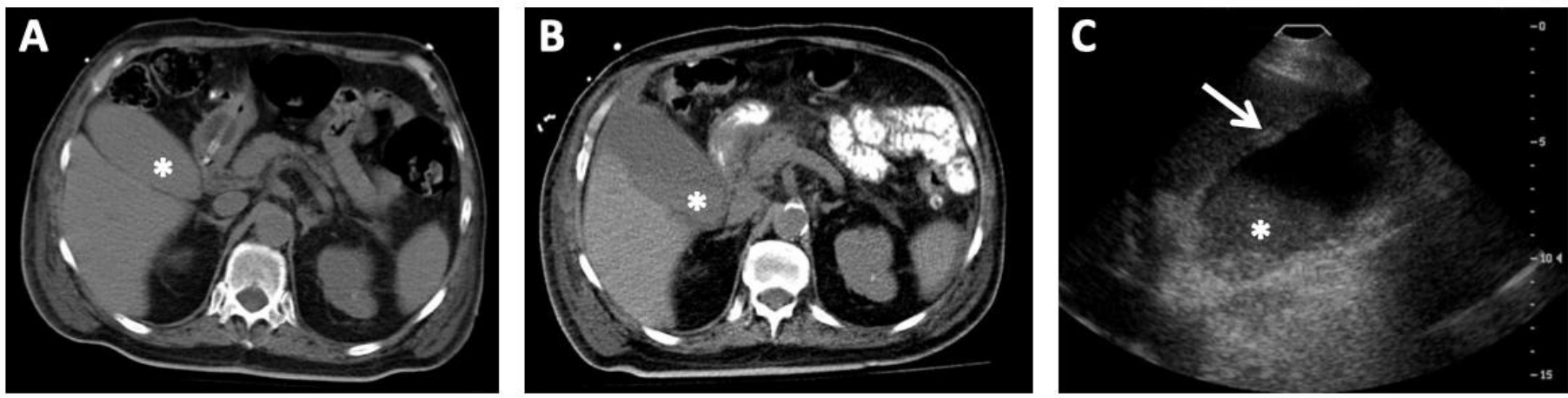

Figure 4: 74-year-old male with acalculous hemorrhagic cholecystitis.

FINDINGS: Unenhanced CT of the abdomen on (A) day 2 and (B) day 9 of hospitalization showed increasing hyperdense (44HU) intraluminal content in the distended gallbladder, interpreted as biliary sludge (*). C) Ultrasound on hospital day 16 showed a distended gallbladder with thickened walls (white arrow) and echogenic layered material presumed to be sludge $(*)$.

TECHNIQUE: A) and B) Axial CT of the abdomen without oral or intravenous contrast. mAs per slice: $200 \mathrm{mAs}$, kilovoltage: $120 \mathrm{kV}$, slice thickness: $5 \mathrm{~mm}$

C) Real time ultrasound of the gallbladder using curved array transducer at $4 \mathrm{MHz}$. 

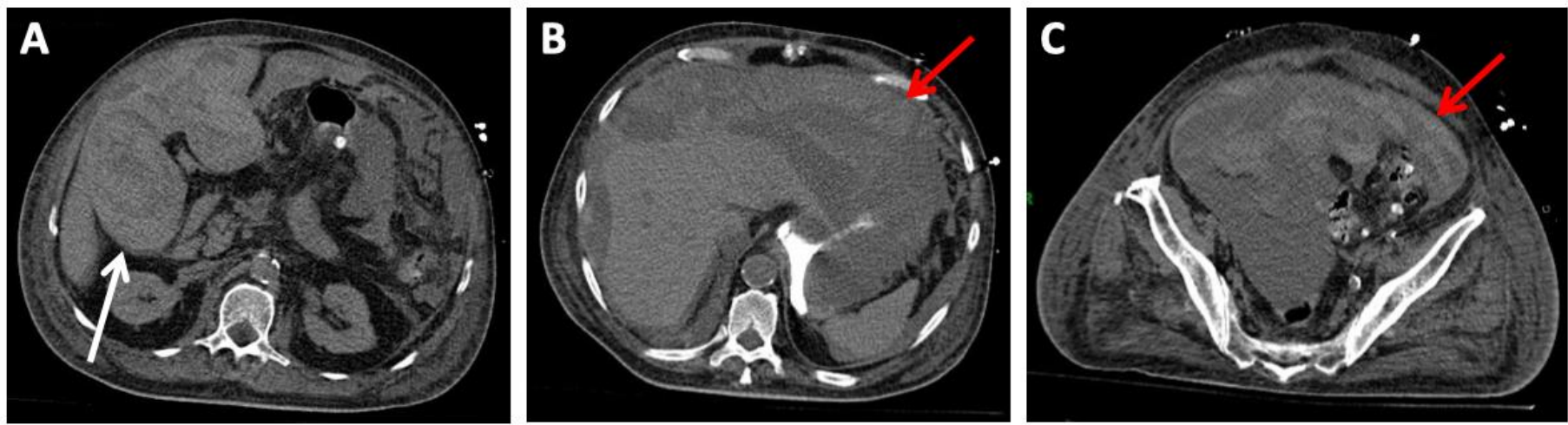

Figure 5: 74-year-old male with acalculous hemorrhagic cholecystitis complicated by massive hemoperitoneum.

FINDINGS: A) Pre-embolization CT scan with gastric contrast through patient's gastrostomy showed a severely distended gallbladder containing hyperdense, heterogeneous blood products (white arrow) and (B) massive hemoperitoneum in the abdomen and (C) pelvis (red arrows).

TECHNIQUE: Axial CT of the abdomen and pelvis without oral or intravenous contrast. mAs per slice: $242 \mathrm{mAs}$, kilovoltage: $120 \mathrm{kV}$, slice thickness: $5 \mathrm{~mm}$
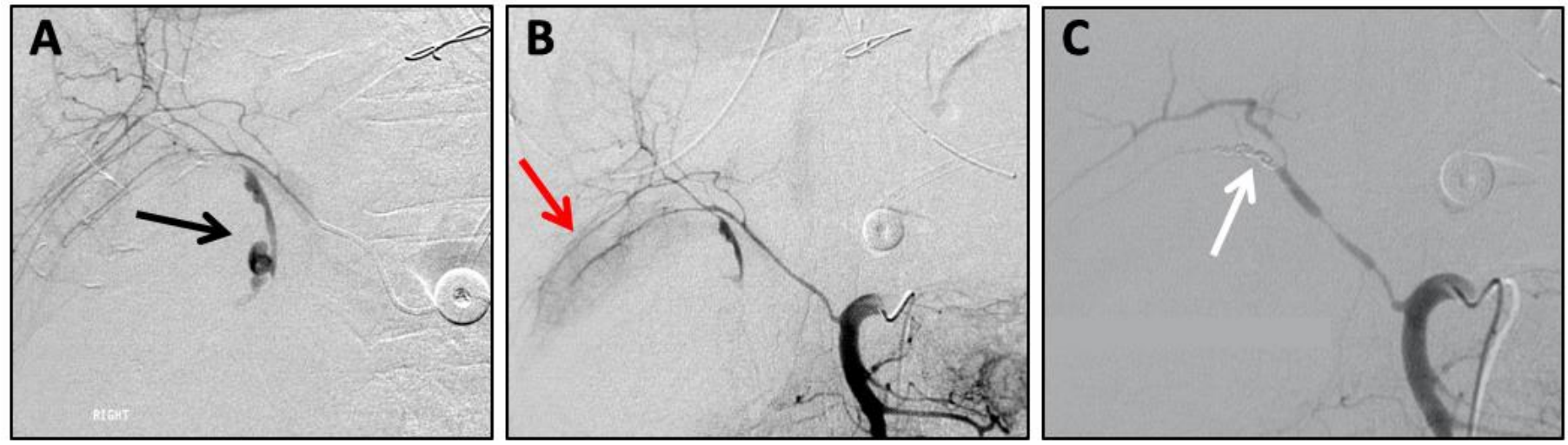

Figure 6: 74-year-old male with acalculous hemorrhagic cholecystitis complicated by massive hemoperitoneum.

FINDINGS: A) Digital subtraction angiography (DSA) showed a replaced right hepatic artery from the superior mesenteric artery. The cystic artery arising from the replaced right hepatic artery later demonstrates irregularity (black arrow) with an actively bleeding pseudoaneurysm. B) Extravasated contrast delineates the contour of the medial border of the gallbladder (red arrow). C) Post-embolization images demonstrate occlusion of the cystic artery with microcoils (white arrow), and subsequent cessation of the extravasation.

TECHNIQUE: SMA angiography with sub-selective catheterization of the cystic artery arising off a replaced right hepatic artery was performed, followed by microcoil embolization of an actively bleeding cystic artery pseudoaneurysm. Embolization material: Polyvinyl alcohol (PVA) particles (500-700 microns) (Contour; Boston Scientific, Natick, MA) followed by seven 3 x $30 \mathrm{~mm}$ and 4 x $30 \mathrm{~mm}$ microcoils (VortX microcoils; Boston Scientific, Natick, MA). Contrast: $168 \mathrm{~mL}$ Omnipaque-240. Fluoroscopy time: 36.2 minutes. Cumulative dose: 1303 mGy. Dose Area Product: 33623 mGym². 


\begin{tabular}{|l|l|}
\hline Etiology & $\begin{array}{l}\text { Hemorrhagic cholecystitis is most often related to gallstone impaction in the gallbladder neck with } \\
\text { erosion of the adjacent cystic artery leading to the formation of a pseudoaneurysm. }\end{array}$ \\
\hline Incidence & Exact incidence is unknown as it is believed to sometimes be unrecognized and misdiagnosed. \\
\hline Gender Ratio & No \\
\hline Age Predilection & No \\
\hline Risk Factors & $\begin{array}{l}\text { Patients with gallstones, hypercoagulable state/platelet dysfunction, anticoagulation therapy, } \\
\text { atherosclerosis, and/or trauma. }\end{array}$ \\
\hline Treatment & $\begin{array}{l}\text { A two-step therapeutic approach should first include embolization of the culprit vessel, followed by } \\
\text { definitive cholecystectomy. }\end{array}$ \\
\hline Prognosis & $\begin{array}{l}\text { Variable prognosis depending on clinical presentation and potentially fatal if not detected. Early } \\
\text { diagnosis is essential to facilitate urgent intervention and surgical treatment. }\end{array}$ \\
\hline Findings on Imaging & $\begin{array}{l}\text { Distended gallbladder containing blood products. The most specific imaging finding is the } \\
\text { identification of a cystic artery pseudoaneurysm. }\end{array}$ \\
\hline
\end{tabular}

Table 1: Summary table of Hemorrhagic Cholecystitis.

\begin{tabular}{|c|c|c|c|c|}
\hline Entity & Ultrasound & CT & MRI & Angiography \\
\hline $\begin{array}{l}\text { Hemorrhagic } \\
\text { Cholecystitis }\end{array}$ & $\begin{array}{l}\text { - Layering, echogenic } \\
\text { debris } \\
\text { - Usually seen in presence } \\
\text { of gallstone(s) } \\
\text { - Wall edema, } \\
\text { pericholecystic fluid } \\
\text { - Distended GB } \\
\end{array}$ & $\begin{array}{l}\text { - Enhancing cystic } \\
\text { artery PSA } \\
\text { - Layering } \\
\text { hyperdensity } \\
\text { - Hemoperitoneum } \\
\text { (if ruptured) }\end{array}$ & $\begin{array}{l}\text { Layering blood products: } \\
\text { - Hyperintense on T1 weighted } \\
\text { sequences } \\
\text { - Isointense/hypointense on T2 } \\
\text { weighted sequences }\end{array}$ & $\begin{array}{l}\text { - Cystic artery } \\
\text { PSA (most } \\
\text { specific } \\
\text { finding) } \\
\text { +/- Active } \\
\text { extravasation }\end{array}$ \\
\hline $\begin{array}{l}\text { Acute } \\
\text { Cholecystitis }\end{array}$ & $\begin{array}{l}\text { Wall edema, } \\
\text { pericholecystic fluid } \\
\text { +/- Gallstones } \\
\text { - Distended GB }\end{array}$ & $\begin{array}{l}\text { - Mural or mucosal } \\
\text { enhancement } \\
\text { - Subserosal edema } \\
\text { - Distended GB }\end{array}$ & $\begin{array}{l}\text { Pericholecystic fluid collection: } \\
\text { - Hypointense on T1 weighted } \\
\text { sequences } \\
\text { - Hyperintense on T2 weighted } \\
\text { sequences }\end{array}$ & $\begin{array}{l}\text { - No cystic artery } \\
\text { PSA }\end{array}$ \\
\hline $\begin{array}{l}\text { Intraluminal } \\
\text { Gallbladder } \\
\text { Mass/ } \\
\text { Carcinoma }\end{array}$ & $\begin{array}{l}\text { - Non-layering, echogenic } \\
\text { mass along the dependent } \\
\text { or nondependent portion } \\
\text { of GB } \\
\text { - Doppler may show } \\
\text { internal flow within mass } \\
\text { lesion }\end{array}$ & $\begin{array}{l}\text { - Intraluminal soft } \\
\text { tissue density mass } \\
\text { - Focal or diffuse } \\
\text { mural thickening } \\
\text { - Post contrast } \\
\text { enhancement }\end{array}$ & $\begin{array}{l}\text { Intraluminal GB Carcinoma: } \\
\text { - Intermediate on T1 weighted } \\
\text { sequences } \\
\text { - Hyperintense on T2 weighted } \\
\text { sequences } \\
\text { - Post gadolinium enhancement }\end{array}$ & $\begin{array}{l}\text { - No cystic artery } \\
\text { PSA }\end{array}$ \\
\hline Biliary Sludge & $\begin{array}{l}\text { - Layering, echogenic } \\
\text { debris } \\
\text { - No internal vascular flow }\end{array}$ & $\begin{array}{l}\text { - Layering } \\
\text { hyperdensity }\end{array}$ & $\begin{array}{l}\text { Gallbladder Sludge: } \\
\text { - Hyperintense on T1 weighted } \\
\text { sequences } \\
\text { - Isointense to mildly } \\
\text { hyperintense on T2 weighted } \\
\text { sequences }\end{array}$ & $\begin{array}{l}\text { - No cystic artery } \\
\text { PSA }\end{array}$ \\
\hline
\end{tabular}

Table 2: Differential diagnosis table for Hemorrhagic Cholecystitis. 


\section{ABBREVIATIONS}

AST $=$ Aspartate Aminotransferase

ALT $=$ Alanine Aminotransferase

$\mathrm{CT}=$ Computed Tomography

DSA = Digital Subtraction Angiography

ERCP = Endoscopic Retrograde Cholangiopancreatography

$\mathrm{GB}=$ Gallbladder

MRI = Magnetic Resonance Imaging

PSA = Pseudoaneurysm

PVA $=$ Polyvinyl Alcohol

SMA $=$ Superior Mesenteric Artery

\section{KEYWORDS}

Hemorrhagic cholecystitis; gallstones; cholelithiasis; hemoperitoneum; cholecystectomy; embolotherapy; microcoil embolization; cystic artery pseudoaneurysm; angiography

\section{Online access}

This publication is online available at: www.radiologycases.com/index.php/radiologycases/article/view/3901

\section{Peer discussion}

Discuss this manuscript in our protected discussion forum at: www.radiolopolis.com/forums/JRCR

\section{Interactivity}

This publication is available as an interactive article with scroll, window/level, magnify and more features.

Available online at www.RadiologyCases.com

Published by EduRad

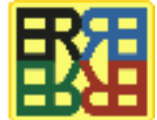

www.EduRad.org 